Environment Conservation Journal 15(3)165-169, 2014

ISSN 0972-3099 (Print) 2278-5124 (Online)

Abstracted and Indexed

\title{
Effects of prenatal exposure to electromagnetic fields on biomarkers of oxidative stress and fertility of F1 generation In-vitro
}

\author{
Jafar Soleimani Rad ${ }^{1}$, Leila Roshangar ${ }^{1}$, Hamideh Gharamaleki ${ }^{1} \bowtie$, Akram Valipoor $^{2}$ and \\ Kaveh Kazemi Kia ${ }^{3}$
}

Received:22.01.2014

Revised: 11.07.2014

Accepted:14.08.2014

\begin{abstract}
The aim of the present study was to evaluate the effects of Electromagnetic Field (EMF) in the prenatal period on biomarkers of oxidative stress and fertility of F1 generation. Material and Methods: The pregnant rats divided to 3 group's treatment (EMF exposure), Sham (off -EMF) and control. After delivery the blood sample of mothers provided and pups were kept until maturity age, and then their fertility was investigated. Results: CAT in treatment group was significantly decreased but no differences in GPX were observed. In treatment group decrease in multicellular embryos and abnormality in cleavage pattern was found. Conclusion: Exposure in EMF cause oxidative stress and reduce fertility.
\end{abstract}

Keywords: EMF, Fertility, F1 generation, Oxidative Stress, Prenatal

\section{Introduction}

Electromagnetic fields (EMFs) may cause an increased activity in free radicals in living organisms and can affect the biological systems (Gulnihal et al, 2008). EMFs interact with human tissues and may have adverse effects on fertility and reproduction. During the last decades it has been a growing concern on the effects of electromagnetic radiations on biological systems in general. This is because of the global introduction of electronic devices on a massive level for communications and data transmission, industry applications, medical/diagnostic and therapeutic purposes that are now new sources of Extremely low Frequency- Electromagnetic Fields (ELFEMF) and radiofrequency microwave radiation (RFR) (Behari and Rajamani, 2012). During recent decades much interest has centered on power lines and their possible association with the health effects including heart functions cell stress (Tokalov and Gutzeit, 2004),memory disorders (Moustafa et al, 2002), melatonin and its relation to sleep and circadian rhythm (DeBruyn et al, 2001),

\footnotetext{
Author's Address

${ }^{1}$ Department of Anatomical Sciences, faculty of medicine, Tabriz University of Medical Sciences, Tabriz-Iran

${ }^{2}$ Departments of Biology, Farhangiyan University, ShahrekordIran

${ }^{3}$ Department of Electrical and Computer Engineering, Islamic Azad University of Bonab, Bonab- Iran E-mail:hamideh.gharamaleki@gmail.com
}

cancers (Kheifets et al, 1995), male and female reproduction and fertility (Al-Akhras et al, 2006). Interesting researches are performed in relation with effects of magnetic fields on cellular stress, reactive oxygen species (ROS) and free radicals, reproductive and fertility (Mohammad Saad, 2003). EMF results in excessive formation of ROS which would result in irreversible tissue damage (Ferniekim and Reynold, 2005). The effects of ELF-EMF are the modification of the normal balance of the free radicals such as superoxide anion $\left(\mathrm{O}_{2}^{-}\right)$, hydroxyl radicals $\left(\mathrm{OH}^{\circ}\right)$ in the organism and modifying the normal pathways of the elimination of these substances (Drogue, 2002). It is well established that changes in intracellular ROS concentration plays an essential role in the modulation of antioxidant defenses (Gulnihal et al, 2008). A living organism has defense systems against different oxidants for e.g. antioxidant vitamins (A, C and E), superoxide dismutase (SOD), catalase (CAT) and glutathione peroxides (GPX) that protect cells against lipid peroxidation. These antioxidant defense systems can be deteriorated by a magnetic field which leads to oxidative stress (Lee et al, 2004). CAT is one of the major enzymes which normally exist in the cells and can be stimulated by variety of factors (Valko et al, 2007). Epidemiological studies on birth defects and abortions in pregnant women working

Copyright by ASEA

All rights of reproduction in any form reserved 
in offices revealed that the EMF generated from a computer monitor can negatively affect human reproduction (Bergqvist, 1984). Many people still believe that, because the energy of the fields is too low to give significant heating, they cannot have any biological effect. However, the evidence that alternating electromagnetic fields can have nonthermal biological effects is now overwhelming (Goldsworthy, 2012). Increased risk of miscarriage caused by ELF-EMF exposure during pregnancy in women, changes in uterus and ovary in rats, congenital deformities and developmental delay in the offspring of mice, reduced fertility in female rats are some outcomes of these investigations in females ( $\mathrm{Li}$ et al, 2002). Also, EMF affects reproductive system and could lead to sub fertility, implantation disorder and congenital malformations (Chernoffet al, 1999). Use of electronic household items and cell phones are reported to decrease fertility potential in men by decreasing sperm count, motility, viability, inducing pathological changes in sperm and testes morphology, and so on (Erogulet al, 2006). Recently it was demonstrated that the exposure for at least $1 \mathrm{~h}$ to a field of $1 \mathrm{mT}$ intensity, $50 \mathrm{~Hz}$ frequency reduced the fertilizing ability of boar mature spermatozoa, tested under in vitro fertilization conditions (IVF), by interfering with different cell activity such as energy metabolism, ionic homeostasis and membrane integrity (Bernabo et al, 2007). According to these considerations, the present research objective was to study the effect exerted by ELF-EMF in prenatal period on biomarkers oxidative stress in pregnant rats and fertility F1 generation in In-vitro condition.

\section{Material and Methods Animals}

In the present research, 18 female Wistar rats and 9 male rat weighting 200-250 g with 2-3 month age were studied. The rats were supplied from animal house of the histology Department Faculty of Medicine, Tabriz University of Medical Sciences. The rats were housed in plastic cages and kept under $12 \mathrm{~h} \mathrm{light/dark} \mathrm{conditions} \mathrm{under} 20-22^{\circ} \mathrm{C}, 50$ $60 \%$ humidity and free access to food and water. The rats were mated and pregnancy was determined by detection of vaginal plagues. The pregnant rats were divided 3 groups of 6 rats in each group, including: experimental, sham and Control.

\section{Study design}

The rats in treatment group were randomly exposed to $3 \mathrm{mT}$ EMF produced by $50 \mathrm{~Hz}$ for 4 hours/day during the pregnancy period. The sham groups were kept in a similar condition without exposure to EMF. The control group was kept in standard condition. After delivery, all rats were bleed from the eye angle were kept in $-80^{\circ} \mathrm{C}$ freezer for biochemical analysis and detection of CAT and GPX. For study of fertility F1 generation in Invitro condition, the neonates were kept up to adolescence and at that time IVF assay with sperm and oocyte preparation were performed.

\section{Biochemical analysis}

\section{CAT level}

Activity of catalase was estimated by measuring its ability to decompose hydrogen peroxide formed due to metabolic reactions into water and oxygen. Hydrogen peroxide has absorbance at $240 \mathrm{~nm}$ and the decrease in optical density (OD) is an indicator of the decomposition of hydrogen peroxide by catalase. The decomposition of the substrate $\left(\mathrm{H}_{2} \mathrm{O}_{2}\right)$ was recorded spectrophotometrically (Schimadzu UV340) at $240 \mathrm{~nm}$ for $60 \mathrm{~s}$ and $30 \mathrm{~s}$ time interval. Catalase activity was expressed as K/g hemoglobin (Luck, 1965, Aebi, 1984).

\section{GPX level}

1unit of glutathione peroxides forms $1.0 \mu \mathrm{mol}$ $\mathrm{NADP}+$ from NADPH per min at $\mathrm{pH} 8.0$ at $25^{\circ} \mathrm{C}$. Enzyme units were defined as the number of micromoles of NADPH oxidized per minute. Results were interpreted as International units per unit per gram of $\mathrm{Hb}(\mathrm{U} / \mathrm{gHb})$ (Beutler, 1984).

\section{Statistical analysis}

The data were analyzed and compared with control and sham group through statistical analysis using with SPSS v.19 software by using T-test and $\mathrm{P}<0.05$ is considered as significant.

\section{Survey In-vitro fertilization (IVF) \\ Sperm preparation}

At first in adult F1 male's epididymis was removed, then, it was fragmented in Hams F/10 media. Finally it was placed in an oven at $37{ }^{\circ} \mathrm{C}$ for 40 min, and then oocytes were fertilized with sperm.

\section{Oocyte preparation}

In the adult F1 female for induce of superovulation, HMG hormone was injected intraperitoneal and after 48 hours HCG hormone was injected. Female rats were anesthetized and their ovaries and fallopian tubes were removed and 
oocytes were isolated in Flushing medium under a light microscope.

\section{IVF assay}

In- Vitro fertilization (IVF) in Universal IVF Medium was performance, then fertilized eggs were preserved in oven $\mathrm{CO}_{2}, 37^{\circ} \mathrm{C}$. After 24 and 48 hours the number of multicellular embryos and their cleavage pattern was assessed by light microscope.

\section{Results and Discussion}

Biochemical analysis showed that in the treatment group CAT level when compared with the control group was found significantly decreasing, while CAT level in Sham group was not found significantly different from the control group. GPX level were found not significantly different between the groups (Table 1).

Table 1: levels of CAT and GPX in control, sham and treatment groups

\begin{tabular}{|c|c|c|c|c|}
\hline Groups & $\begin{array}{l}\text { CAT } \\
\text { (k/g Hb) }\end{array}$ & $\begin{array}{l}\text { P- } \\
\text { value }\end{array}$ & $\begin{array}{l}\text { GPX } \\
\text { (U/g } \\
\text { Hb) }\end{array}$ & $\begin{array}{l}P \text { - } \\
\text { value }\end{array}$ \\
\hline Treatment & $\begin{array}{l}132.10 \pm \\
2.49\end{array}$ & \multirow[t]{2}{*}{$0.023 *$} & $\begin{array}{l}28.95 \pm \\
7.43\end{array}$ & \multirow[t]{2}{*}{0.85} \\
\hline Control & $\begin{array}{l}140.42 \\
\pm 2.66\end{array}$ & & $\begin{array}{ll}28.1 & \pm \\
7.87 & \end{array}$ & \\
\hline Sham & $\begin{array}{l}139.89 \pm \\
2.54\end{array}$ & 0.35 & $\begin{array}{l}30.78 \pm \\
4.07\end{array}$ & 0.47 \\
\hline
\end{tabular}

Values represent the means \pm SD, $*$ P $<0.05$

The results of present study state that maternal exposure to ELF-EMF from 0 day of gestation lead to decreasing of CAT level in treated groups in

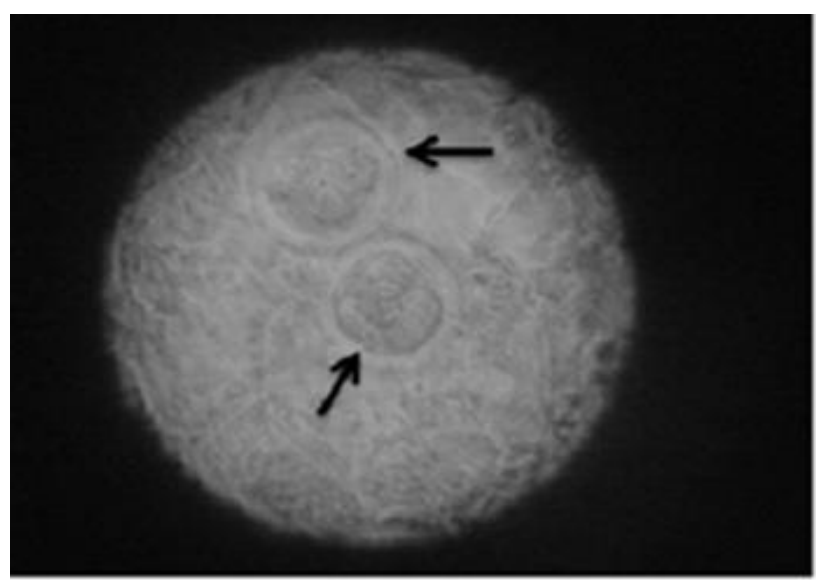

Fig 1: Multicellular embryo in treatment group after 48 hours in In-vitro culture medium Note blastocyst with irregular cleavage (arrow) comparison with control group (Table 1). These results indicated that, acute exposure to EMF may modulate the oxidative stress of free radicals by reducing the activation of CAT which is free radical scavenger. Changes in activities of antioxidant enzymes were found as follow 10-day or 2-month exposures to MFs at 0.5-50 $\mu \mathrm{T}$. (Markkanen, 2009). In the present study, the GPX level was not found significantly different between groups (Table 1). It has been showed that chronic (90 days) exposure to $50 \mathrm{~Hz}$ EMF does not cause oxidative stress. They showed that the concentration of antioxidant enzymes in the blood of mice did not increase (Martinez et al, 2010). It showed that SOD and GPX activities altered in expose of ELF-EMFs, However not found significant changes in catalase levels (Tiwari et al, 2013). Some studies have shown increased oxidative-stress in human fibroblasts under ELFEMFs exposure (Focke et al, 2010). Levels of catalase, GPX and SOD were significantly increased in the liver and lungs of mice exposed to EMF for 8 weeks (Martinez et al, 2010).The different results of different studies can be explained by the differences in the duration exposure time, intensity and frequency of EMF.

The photomicrograph observations and investigation of percentage multicellular embryos (blastocysts) showed that rats exposed to magnetic fields during the development period in comparison with control group have impaired fertility and their fertility has decreased (Table 2) (Fig 1, 2). Results in sham group were found not significantly different from the control group.

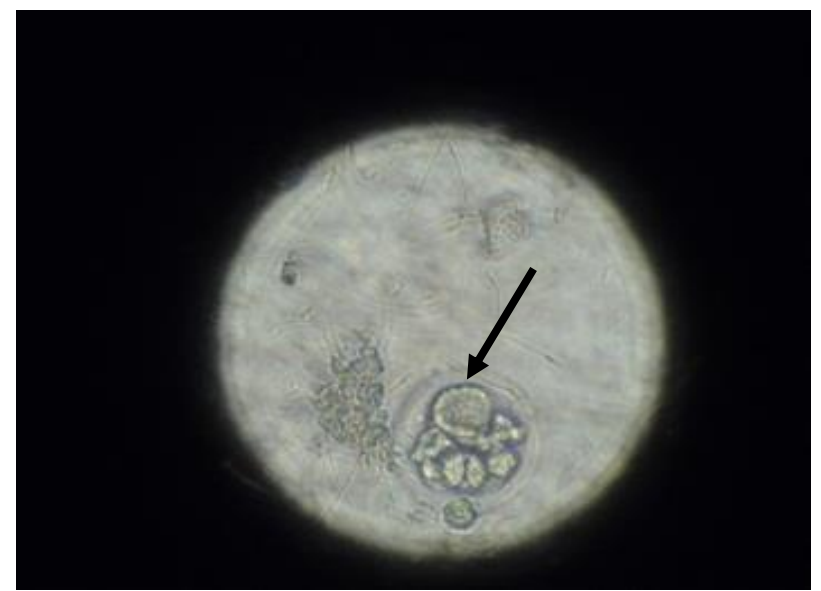

Fig 2: Multicellular embryos in control group after 48 hours In In-vitro culture medium Note blastocyst with normal cleavage (arrow) 
Rad et al.

Table 2: Comparison percentage of multicellular embryos in IVF culture medium in treatment (Exposure EMF) with control group

\begin{tabular}{|l|l|l|l|}
\hline Groups & $\begin{array}{l}\text { Number of oocyte } \\
\text { preparation }\end{array}$ & $\begin{array}{l}\text { Number of proliferated } \\
\text { oocyte }\end{array}$ & $\begin{array}{l}\text { Percentage of } \\
\text { multicellular embryos }\end{array}$ \\
\hline Treatment & 16 & 9 & $56 \%$ \\
\hline Control & 26 & 20 & $77 \%$ \\
\hline
\end{tabular}

The results of present study showed that rats exposed to magnetic fields during the development period at the time of puberty, have impaired fertility. The teratogenicity effects of chemical and physical environmental agents are often related to their ability to damage DNA (Aydin, 2007). In the present investigation, significant decreases in fertility and catalase activities were observed in puberty of F1 generation. Reactive oxygen species (ROS) and oxidative damage to bimolecular as a mechanism of chemical and physical environmental agents may contribute to male infertility by reducing sperm function (Atessahin et al, 2006).

When female mice were super ovulated and mated following exposure to a $50 \mathrm{~Hz}$, EMF at $0.5 \mathrm{mT} 4$ hours per day, 6 days a week for 2 weeks, and the number of blastocysts was significantly decreased (Borhani et al, 2011), that this suggests exposure to EMF in the pre-implantation stage could have detrimental effects on embryo development. Male and female rats exposed to magnetic fields $50 \mathrm{~Hz}$ for 90 days showed a decrease in fertility (AlAkhras et al, 2001). It showed that magnetic field exposure interrupts the process of the gamete fusion but did not influence gametes, embryos, or embryonic development (Borhani et al, 2011). It showed that in-vitro exposure to $50 \mathrm{~Hz}$ magnetic field did not induce considerable difference in the number of mouse early blastocyst and late blastocysts (Hanneleet al, 2001).In parallel, Pafkova et al, (1996) found no significant alterations in embryogenesis of rat and chick embryos, exposed to $50 \mathrm{~Hz}$ EMF. Importantly, the reproductive hazard of EMF exposure in nonpregnant young women has not been studied well. Together, the effect of EMF exposure on embryonic development is still controversial, but some negative effects of EMFs have been reported in some animal models (Gye and Park, 2012).

\section{Conclusion}

The results of this study indicated that ELF-EMF in prenatal period cues of oxidative stress in maternal and decrease of fertility in F1 generation that such as study of Behari and Rajamani, (2012) maybe cause of Sperm DNA damage that it regarded as a potential risk factor to the development of normal embryos leading to impaired embryonic development.

\section{References}

Aebi, H., 1984.Catalase in Vitro method in Enzymology, 121126.

Al-Akhras, M.A., Elbetiaha, A., Hasan, M.K., Al- Omari, I.A., Darmani, H., Albiss, B., 2001.Effects of extremely lowfrequency magnetic fields on fertility on adult male and female rats. Bioelectromagnetic, 22: 340-344.

Al-Akhras, M. A., Daramani, H. and Elbetieha, A., 2006. Influence of $50 \mathrm{~Hz}$ magnetic field on sex hormones and other fertility parameters of adult male rats. Bioelectromagnetics, 27: 127-131.

Atessahin, A., Karahan, I., Turk, G., Gur, S., Yylmaz, S., Ceribasy, A.O., 2006. Protective role of lycopene on cisplatin-induced changes in sperm characteristics, testicular damage and lipid peroxidation in rats. Reprod. Toxicol, 21:42-47.

Aydin, M., Turk, G., Yuksel, M., Ceviek, A., Apaydin, A.M.,Yilmaz ., 2007. Effect of electromagnetic field on the sperm characteristics and histopathological status of testis in rats.Medycyna Wet, 63: 178-183.

Behari, J. and Rajamani, P., 2012. Electromagnetic Field exposure effects (ELF-EMF and RFR) on fertility and Reproduction. Bio Intiative. Biologicallyy- based exposure standards for low-Intensity Electromagnetic Radiation, Section 18:1-37

Bergqvist, U.O., 1984.Video display terminals and health.A technical and medical appraisal of the state of the art.Scand $\boldsymbol{J}$ Work Environ Health, 2:1-87.

Bernabo, N., Tettamanti, E., Pistilli, M.G., Nardinocchi, D., Berardinelli, P., Mattioli, M., 2007. Effects of $50 \mathrm{~Hz}$ 
extremely low frequency magnetic field on the morphology and function of boar spermatozoa capacitated in vitro. Theriogenology, 67: 801-815.

Beutler, 1984. "Red Cell Metabolism, A Manual of Biochemical Methods," Grune\& Stratton, Inc., New York: 175-195.

Borhani, N., Rajaei, F., Salehi, Z., Javadi, A., 2011. Analysis of DNA fragmentation in mouse embryos exposed to an extremely low-frequency electromagnetic field Electromagn Biol Med, 30:246-252.

Chernoff, N., Rogevs, J.M., Kavet, R. 1999. A review other literature on potential reproductive and developmental toxicity of electric, and magnetic fields. J Toxicology, 14: 91-125.

DeBruyn, L.,deJager, L., and Kuyl, J., 2001. The influence of long-term exposure of mice to randomly varied power frequency magnetic fields on their nocturnal melatonin secretion patterns. Environmental Research, 85: 115-121.

Drogue, W., 2002. Free radicals in the physiological control of the cell function. Physiological Reviews, 82: 47-95.

Erogul, O., Oztas, E., Yildirim, I., Kir, T., Aydur, E., Komesli, G., Irkilata, H.C., Irmak, M.K., Peker, A.F., 2006. Effects of electromagnetic radiation from a cellular phone on human sperm motility: an vitro study. Arch Med Res, 37:840-3.

Focke, F.,Schuermann, D., Kuster, N., Schar, P., 2010. DNA Fragmentation in Human Fibroblasts under Extremely Low Frequency Electromagnetic Field Exposure. Mutation Research, 683: 74-83.

Ferniekim, J. and Reynold, A., 2005.The Effects of electromagnetic fields from power lines Avian Reproductive Biology and Physiology. Journal of Toxicology and Environmental Health, 8: 127-140.

Goldsworthy, A., 2012. The biological effects of weak Electromagnetic fields: problems and solutions. Springerverlag Berlin Heidelbery, 3: 247-267.

Gye, M.C. and Park, C.J.,2012. Effect of electromagnetic field exposure on the reproductive system.Clin Exp Reprod Med, 39: 1-9.

Gulnihal, C.,Ayse, C.,Seyhan, N.,2008. Effects of various extremely low frequency magnetic fields on the free radical processes, natural antioxidant system and respiratory burst system activites in the heart and liver tissues.Indian journal of biochemistry \& Biophysics, 45: 326-331.

Luck, H., 1965.Methods of Enzymatic Analysis, 2nd Edition, Academic Press, New York.
Hannele, H., Jukka, J., Hannu, K.,2001. Development of preimplantation mouse embryos after exposure to a $50 \mathrm{~Hz}$ magnetic field in vitro. Toxicol Lett, 122: 149-155.

Kheifets, L. I., Afifi, A.A., Buffler, P.A., Zhang, Z.W.,1995. Occupational electric and magnetic field exposure and brain cancer: a meta-analysis. Journal of Occupational and Environmental Medicine, 37: 1327-1341.

Lee, B.C., Jong, H.M., Lim, J.K., 2004. Effects of extremely lowfrequency magnetic field on the antioxidant defense systemin mouse brain: a chemiluminescence study. $\boldsymbol{J}$ Photochemical Photobiology B, 73: 43-48.

Li, D.K., Odouli, R.W.,Janevic, S.,Golditch, T., Bracken, T.D.,2002. A population based prospective cohort study of personal exposure to magnetic fields during pregnancy and the risk of miscarriage. Epidemiology, 13: 9-20.

Markkanen, A., 2009. Effects of electromagnetic fields on Cellular Responses to Agents causing oxidative Stress and DNA Damage. Kuopio Univ Public, Nat and Environ Sci, 253: $1-59$

Martinez-Samano, J., Torres-Dorres, P., Juarez-Oropeza, M., Elias-Vinas, D., Verdugo-Diaz, L.,2010. Effects of acuteelectromagnetic field exposure and movement restraint on antioxidant System in liver, heart, kidney and plasma of Wistar rats: A preliminary report. Journal Radiat Biol, 86:1088-1094.

Saad El-Din, I.M., 2003. Effects of electromagnetic field on some physiological Parameters in Rat. Ph.D. Thesis submitted to Zagazig University.

Moustafa, R. M., Moustafa, Y. M. and Ennaceur, A. K., 2002. Effects of exposure to extremely low frequency magnetic field of $2 \mathrm{G}$ intensity on memory and corticosterone level in rats. Physiology and Behavior, 76: 589-595.

Pafkova, H., Jerabek, J., Tejnorova, I., Bednar, V., 1996.Developmental effects of magnetic field $(50 \mathrm{~Hz})$ in combination with ionizing radiation and chemical teratogens.Toxicol Lett, 88: 313-316.

Tiwari,R., Bhargava, S., Chandra, A., 2013. The Potential Bio effects of Extremely Low Frequency Electromagnetic Fields on Melatonin Levels \& Related Oxidative Stress in Electric Utility Workers Exposed to $132 \mathrm{kV}$ Substation. Journal of Electromagnetic Analysis and Applications, 5: 393-403.

Tokalov, S.V. and Gutzeit, H.O., 2004. Weak electromagnetic fields $(50 \mathrm{~Hz})$ elicit a stress response in human cells. Environmental Research, 94: 145-151.

Valko, M., Leibfritz, D., Moncol, J., Cronin, M., Mazur, M., Tesler, J., 2007.Free radicals and antioxidants in normal physiological functions and human disease. The International journal of Biochemistry \& cell Biology, 39: 44-84. 